\title{
Recent advances in mechanoluminescent polymers
}

\author{
Yuan Yuan, Wei Yuan and Yulan Chen*
}

\begin{abstract}
In recent years, mechanoluminescence from polymers is emerging as a new cutting-edge area of polymer mechanochemistry research. It refers to the release of energy from polymers in the form of light when they are under various mechanical stimuli. To spur more researchers to join in such interesting and new burgeoning area, and promote its development to practical applications, in this review, we try to briefly summarize the recent advances in mechanoluminescent polymers with the aspects of non-covalent, covalent, and cascade reactions systems. We pay much attention on the applications of such polymer systems in molecular level failure and stress sensors, and give a perspective of their potential applications in novel energy conversion materials and devices, as well as self-healing materials.
\end{abstract}

Keywords: mechanochemistry, mechanoluminescent polymer, stress sensor

\section{INTRODUCTION}

Mechanochemistry refers to using mechanical energy to generate chemical and physical property changes which can be harnessed in a variety of applications [1-3]. Actually, mechanochemistry is ubiquitous in biological systems and plays an essential role in realizing many vital functions of living organisms [4-8]. For instance, cell adhesion and growth, activation of ion channels, clotting of blood and hearing, all rely on the well-regulated mechanosensing and mechanochemical transduction processes. As for the abiotic aspects, since the prefix "mechano" is well established as a term for grinding, milling and breaking, it is no doubt that the practical mechanochemistry has been with us for a very long time [2]. Making fire by friction or by drilling wood is common processes that include mechanochemical steps. Later on, researchers were able to manipulate inorganic materials and metal alloys by ball milling [9]. And in macromolecular science, polymer mechanochemistry started in 1930s, when Staudinger [10] interpreted the decrease in molecular weight upon mastication of a polymer as the mechanical rupture of macromolecules. The increasing demands for polymeric materials in modern life promoted the mechanical degradation of polymers as a subject of the intense study of polymer mechanochemistry for decades, all of which are practically important while in relatively nonspecific ways.

Nowadays, polymer mechanochemistry has become a burgeoning area of mechanochemistry research. Polymers permeate every aspect of daily life. They offer a wide range of useful properties (light weight, toughness, elasticity, and processability, etc.) and their long chains are suitable to act as "force handles" to transiently accumulate and transfer mechanical energy along the backbone [3]. These characters of polymers bestow mechanical energy flexible and stretchable features, which are promising to open up the breakthrough of smart materials, soft active devices, wearable sensors and roll-up displays [11]. In these scenarios, mechanical force becomes a novel type of flexible power source with directional nature mediated by polymer backbones, which is largely different from that of thermal, photonic and electric activation. Nevertheless, the opportunities in polymer mechanochemistry arise only when the manipulation of chemical structures and physical properties of polymeric materials by applying macroscopic mechanical force can be achieved in a controlled and pre-programmed manner, similar to physiological processes. Such a topic has only very recently begun to receive attention from a number of polymeric and materials chemists or scientists. As a result, the focus of studying mechanochemical degradation of polymers has shifted from optimization of processing properties to understand mechanochemical events at molecular level and to the development of functional mechano-responsive materials. The last decade has witnessed tremendous

Department of Chemistry, Tianjin Key Laboratory of Molecular Optoelectronic Sciences, Tianjin University, and Collaborative Innovation Center of Chemical Science and Engineering, Tianjin 300072, China

* Corresponding author (email: yulan.chen@tju.edu.cn ) 
progress on the creation of mechano-responsive polymers [12-20]. Mechanical force has been used, for instance, to activate ring-opening $[13,17,21]$ and cycloreversion reactions $[14,15,22]$, to trigger latent polymeric catalysts [12,23-25], to guide "flex activation" $[16,26]$, to induce cross-linking reactions $[24,27,28]$, to assemble or disassemble supramolecular polymers in a controlled manner [29-34], and so on.

Among diverse responses derived from mechanical trigger, the polymers that elicit a visible output have attracted widespread attention. Very recently, mechanoluminescence from polymers is emerging as a growing research field, which refers to the release of energy from polymers in the form of light when they are under various mechanical stimuli [35]. Mechanoluminescence is a very intriguing phenomenon that is found potential applications for $\mathrm{X}$-ray generators [36], bioimaging [37] and stress sensors $[38,39]$. Alongside stress sensors, the quest for strong and durable advanced polymer-based materials requires fundamental understanding and sensitive reporting the specific molecular level details regarding their unavoidable failure events. What is known and appreciated is that the force-induced scission of stress-bearing bonds often plays a critical role; that is, bonds often break during fracture [40]. Polymer mechanoluminescence is advantageous over the traditional technical probes for chain scission (including NMR, ESR, IR spectroscopy) in the aspects of spatial and temporal resolution [41]. Its intense visible signal offers a self-indicating method of mapping molecular stress distribution and monitoring the rare molecular scission events that precede failure in polymers with greater sensitivity. Deservedly, much current activity in this area, particularly in the development of intense luminescent probes has progressed considerably over the past few years and is still undergoing.

This review provides a brief overview of the recent research efforts of polymer mechanoluminescence. Firstly, examples of mechanoluminescent polymers with supramolecular mechanophores are discussed. Then, we focus on mechano-responsive polymers that can radiate light (including fluorescence and chemiluminiscence) coupling directly to bond scission reactions. In the end, catalytic mechanoluminescence, based on polymer composites capable of cascade mechanical energy transformation were introduced. In each part, the molecular design of mechanophores and polymer frameworks, their experimental development, the various strategies for mechanical energy transduction, and how they relate to stress sensors will be described. Finally, we end up the review with outlining challenges and opportunities in this specific research area.

Other aspects of mechanoluminescence, such as those involved in the milling of crystals, displacement of metal oxide lattices [42], triboluminescence from complexes [43-48], and sonoluminescence [49-57] are well known and important fields, but they will not be discussed here. And for a more comprehensive coverage of the field of polymer mechanochemistry, the reader is referred to several recent outstanding reviews $[3,11,26,58-62]$.

\section{MECHANOLUMINESCENT POLYMERS WITH SUPRAMOLECULAR MECHANOPHORES}

The combination of the molecular structure and supramolecular organization of the polymer components is considered to be an effective route to obtain products with versatile features. Indeed, different non-covalent interactions have begun to be utilized in mechano-responsive polymers, so that the selective dissociation of supramolecular motifs was realized under relatively weak and tunable mechanical force, meanwhile imparting polymers with adaptive properties.

The basic principles of the mechanoluminescent polymers with supramolecular mechanophores is founded on distinguishable changes in emission associated with the conversion between the aggregated form and the isolated (monomeric) form of the embedded $\pi$-conjugated dyes in the continuous polymeric matrix as a consequence of mechanical stimuli [63-65] (Fig. 1). The first example based on this principle was illustrated by Löwe et al. [30] as early as 2002 . In a linear low-density polyethylene (LLDPE) matrix, the blended dye molecules, a kind of oligo( $p$-phenylenevinylene) (OPV) derivatives which com-

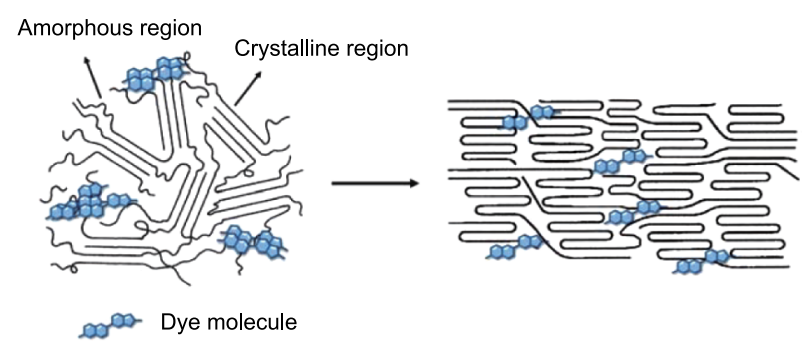

Figure 1 Schematic representation of mechanoluminescent polymers with distinguishable changes in emission associated with the conversion between the aggregate form and the isolated form of the embedded $\pi$-conjugated dyes in a semicrystalline polymeric matrix under mechanical stimuli (Reproduced with permission from Ref. [63], Copyright 2011, the Royal Society of Chemistry). 
prise electron-withdrawing cyano groups as part of the conjugated system, were estimated as molecular probes of film deformation. Upon tensile deformation, the dyes distribution responded accordingly from aggregating excimers to monomeric state, leading to substantial photoluminescence change. The luminescence thus changed from orange to green for the dye $\mathbf{1}$ blend and from green to blue for the dye 2 blend (Fig. 2a). The dyes featured mechanoluminescent properties only when they were doped in polymer matrices due to their critical role in transferring mechanical force under deformation.

Other polymer matrix, such as polyethylene terephthalate (PET) and PET glycol (PETG) were selected as well. However, in such cases, the modification of dye $\mathbf{1}$ was required because the compound was extremely insoluble in the PET- or PETG-based matrix and failed to undergo microphase separation, as well as excimer formation. To address these issues, the methyl group at the ends of dye $\mathbf{1}$ was replaced with an 18-carbon long alkyl chain, affording dye 3 . The blend of LLDPE and dye 3 also exhibited luminescent color change. A further detailed investigation of the phase dispersion behavior of dyes and crystallinity of polymer matrices showed that the ability of polymer host for dye aggregate break-up is related to the plastic deformation process of polymer crystallites. It was found that high degree of crystallinity and lamellar microstructure of polymers promoted efficient aggregate disruption and significant optical changes of the blend films [31,32,64]. In situ luminescent mechanical experiments demonstrated that the fluorescence color changes were reversible and nicely mirrored the stress-strain response of the materials.

The strength of the $\pi-\pi$ stacking interaction and the optical properties of the mechanophores can be tailored over a broad range. Beyond cyano-OPVs, other chromophorepolymer blends that have a strong tendency towards excimer formation of the mechanophores have also been explored for mechanosensing purposes. For example, Pucci and co-workers $[29,33,34]$ performed comprehensive systematic studies with a commercially available dye, bis(benzoxazolyl)stilbene (BBS, Fig. 2a, dye 4), and polymer matrices. The polymer host could be poly(propylene) (PP), LLDPE, and poly(1,4-butylene succinate) (PBS), and thermoplastic polyurethane (TPU), etc. All in all, the large number of available semicrystalline polymer matrices and fluorescent dyes boost the development of plenty of new materials capable of transducing weak force into luminescence.

Another important category of mechanoluminescent materials are based on luminophores with aggregation-induced emission (AIE) features, namely, AIEgens. Luminescence change with mechanical force has been commonly observed in a great quantity of AIEgens. It is noted that the mechanochromic effect is often exploited in small molecular AIEgens, whereas, the combination of mechanical active AIEgens with macromolecular scaffolds results in numerous possibilities to tune the molecular structure, functionalities and mechanical strengths of the macromolecular systems. One of the distinguished exam- a
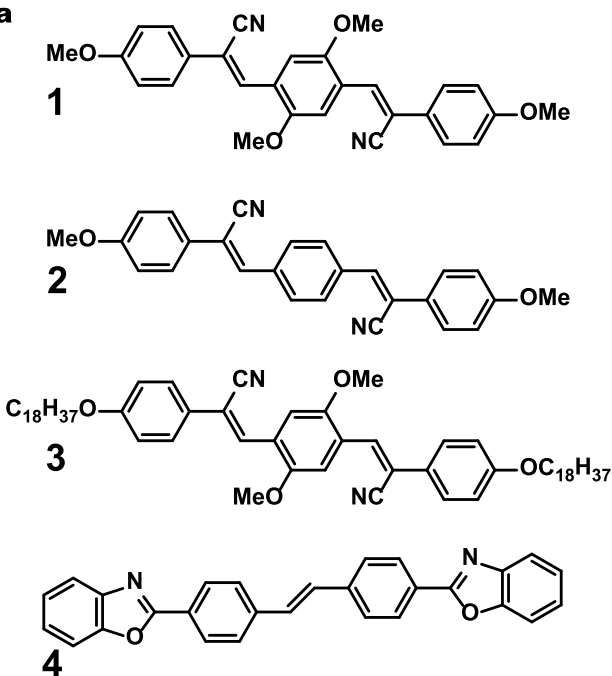

b

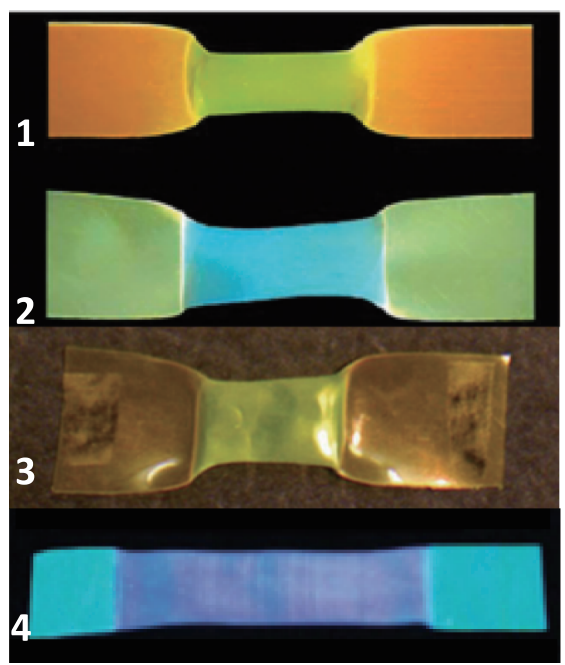

Figure 2 Non-covalent mechanoluminescence dyes and polymer blends: (a) chemical structures of cyano-OPV derivatives dye 1-3 and BBS 4. (b) Under UV irradiation pictures of blends LLDPE-dye 1 and LLDPE-dye 2 (reproduced with permission from Ref. [66], Copyright 2009, Nature Publishing Group.); PET-dye 3 (reproduced with permission from Ref. [64], Copyright 2006, American Chemical Society); PP-dye 4 (reproduced with permission from Ref. [33], Copyright 2005, WILEY-VCH). 
ples is illustrated by Hu's group in 2014, in which a built-in aggregatochromic probe was developed to investigate the morphological changes such as deformation of shape memory polymers (SMPs) induced mechanical force, solvents, and thermal treatment [67]. In this work, the material was made of memory chromic polyurethane with tetraphenylethylene (TPE) units covalently connected to the soft-segments (PCL). It exhibited memory chromic property that represented by emission intensity changing under deformation. When stretched (Fig. 3, process 1), the emission of the TPE-based SMPs was decreased as a result of the deaggregation of TPE units and the reduction in the local luminogen concentration. When the soft segments were molten (process 2) or dissolved in solvent (process 3 and 4), the shape recovery switch was open, and the AIE units were free from crystal binding and can migrate easily to larger areas, thus the emission intensity reduced or disappeared. Such simple approach enabled the material with reversible mechanochromic, solvatochromic, thermochromic, and shape memory effect.

\section{MECHANOLUMINESCENT POLYMERS WITH COVALENT MECHANOPHORES}

Compared to the mechanoluminescent polymers with supramolecular mechanophores, their covalent counterparts are advantageous in terms of their long-term stability and tunable activation stresses. Pioneering work regarding covalent mechanophore that displays desired responsive behavior was investigated by Davis and co-worker [21].

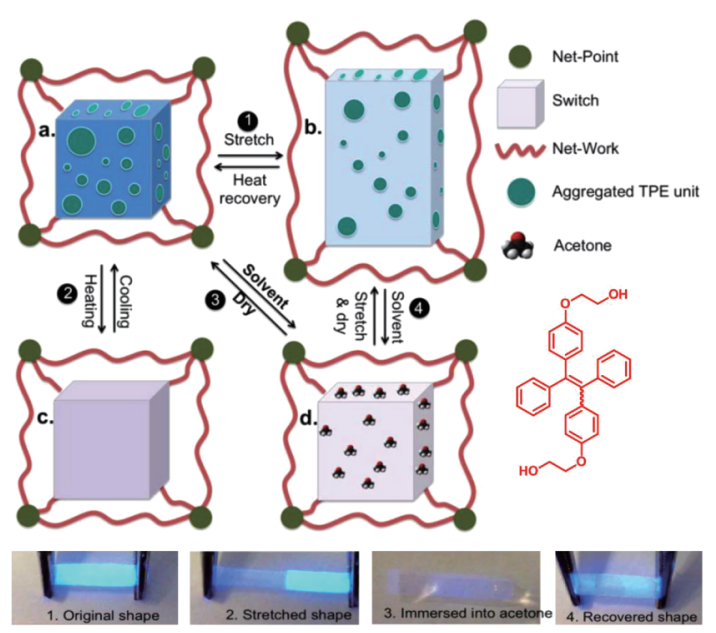

Figure 3 A model to illustrate the molecular mechanism: (1) during stretch-recovery process, (2) heating-cooling process, (3) solvent-dry process and (4) solvent induced shape recovery process (reproduced with permission from Ref. [67], Copyright 2014, WILEY-VCH).
They developed a kind of mechanochromic polymers by covalently incorporating spiropyran (SP) into the polymer backbones (SP-linked polymethacrylate (PMA) or SP crosslinked polymethyl methacrylate (PMMA)). Upon deformation of the materials, either by tensile or compressive force, the color of the elastic polymer films or glassy beads turned from colorless to red. The mechanism of the color changing is based on the stress-induced $6 \pi$-electron electrocyclic ring-opening of SP into the red merocyanine (MC) (Fig. 4). They consequently published comprehensive studies on polymeric spiropyran, illustrating that $\mathrm{SP}$ is a mechanochromic force sensor that could be applied in a variety of polymer substrates.

Following their discovery of force induced coloration that the color of polymer films changes distinctively under mechanical loading, interests are then focused on mechanically induced luminescence in which significant enhancement in sensitivity over mechanochromsim in the mapping of bond scission is expected. Chung et al. came up with the way by incorporating specific strained dimer of fluorophore in polymer backbones. The corresponding monomeric structures, such as cinnamate (Fig. 5a) [68] and anthracene (Figs 5b and c) [69], that emit strong fluorescence, can be regenerated along propagating cracks of the polymer films. The exact position of cracks therefore could be easily detected. Later on, Kean et al. [70] reported a coumarin dimer as the mechanoluminescent motif to report stress distribution in PMA (Fig. 5d). Moreover, the $\pi$-extension of anthracenes and their incorporation into polymeric Diels-Alder adducts exhibited mechanochemical activity that underwent cycloreversion reaction by releasing $\pi$-extended anthracene with intense fluorescence emission when it was subjected into mechanical force (Figs $5 e$ and $\mathrm{f}$ ). Compared to bare anthracene, the $\pi$-extension of mechanophore provides an excellent method to substantially improve the sensitivity of these stress-reporting optical probes [71].

Polymers with biomechanophores represent another kind of promising fluorescent sensors due to the inherent optical properties from many biomacromolecules. In 2009, the Clark's group designed a protein based sensor to detect structural deformation in a polymer matrix [72]. The donor-acceptor pair of fluorescent proteins (enhanced cyan fluorescent protein (eCFP) and enhanced yellow fluorescent protein (eYFP)) offers the possibility for Förster resonance energy transfer (FRET) changing when a sufficient force is applied to the protein-polymer hybrid and changes the distance of two halves of the thermosome (Fig. 6). Makyła et al. [73] fabricated class-fiber-reinforced 


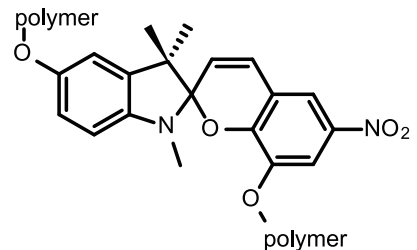

b

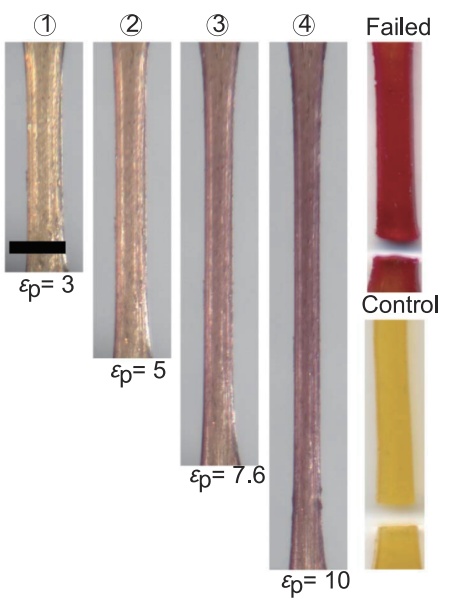

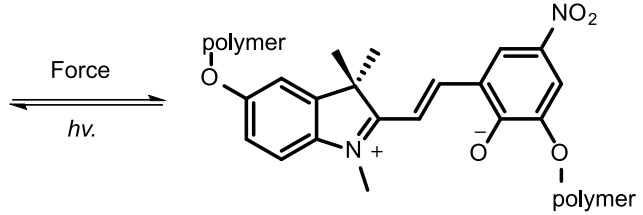

c

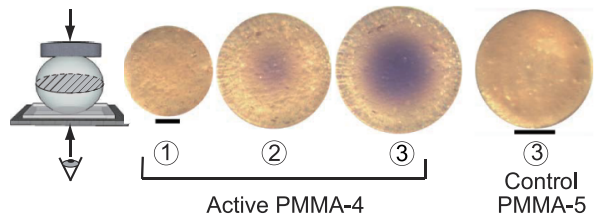

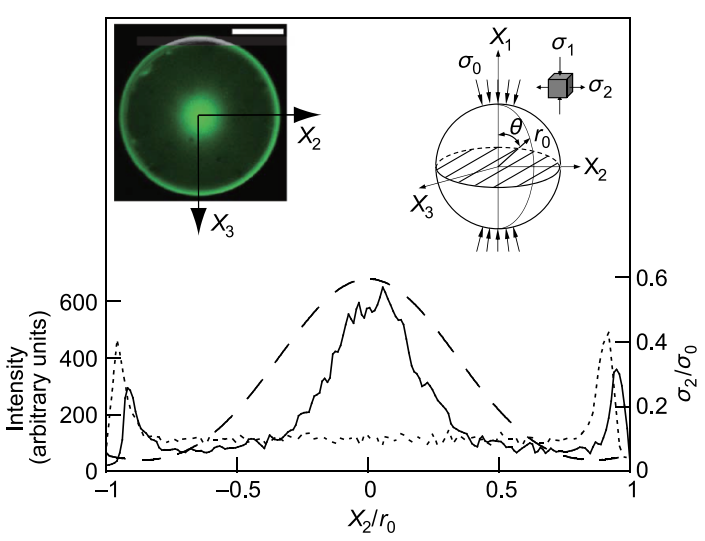

Figure 4 Mechanochromic polymers as stress reporter: (a) mechanochromism in polymers by force induced ring opening of SP to merocyanine; (b) accumulation of plastic strain and color change for SP-linked PMA bulk sample subjected to tensile testing; (c) measured fluorescence intensity in the equatorial plane for a bead of a SP crosslinked PMMA deformed just past the yield point (reproduced with permission from Ref. [21], Copyright 2009, Nature Publishing Group).
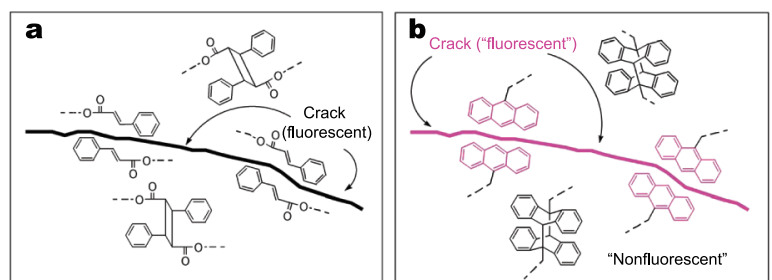

d<smiles>CC(C)(C)C(=O)OCCOc1ccc2c(c1)OC(=O)[C@H]1C(=O)Oc3cc(OCOC(=O)C(C)(C)C)ccc3[C@H]21</smiles><smiles>Cc1cc(=O)oc2cc(OCOC(=O)C(C)(C)C)ccc12</smiles>

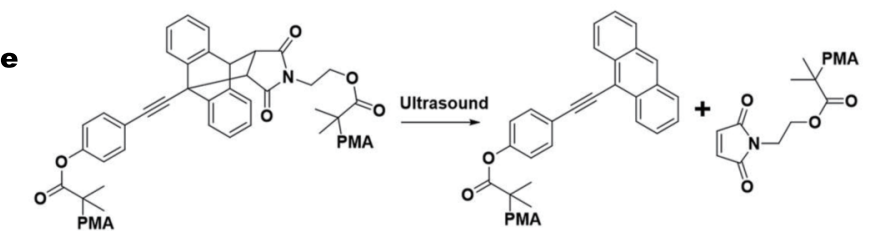

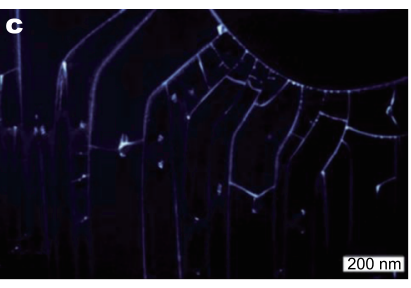
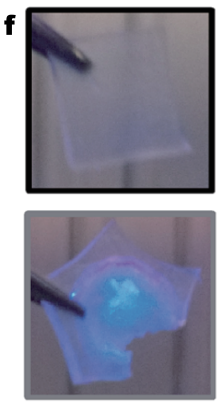

Figure 5 Examples of mechanically induced light associated with cycloreversion reactions: crack sensor with (a) cinnamate dimer (reproduced with permission from Ref. [68], Copyright 2008, Elsevier); (b) anthracene dimer (reproduced with permission from Ref. [69], Copyright 2012, the Royal Society of Chemistry); (d) coumarin dimer; (e) $\pi$-extended anthracene and maleimide Diels-Alder adduct as the mechanophore; photographs of (c) the fluorescent cracks formed in films of anthracene-dimer linked poly-AA (reproduced with permission from Ref. [69], Copyright 2012, the Royal Society of Chemistry); (f) crosslinked poly(hexyl methacrylate) (PHMA) network with $\pi$-extended anthracene and maleimide Diels-Alder adducts, showing intense blue fluorescence emission after compression (reproduced with permission from Ref. [71], Copyright 2016, the Royal Society of Chemistry). 


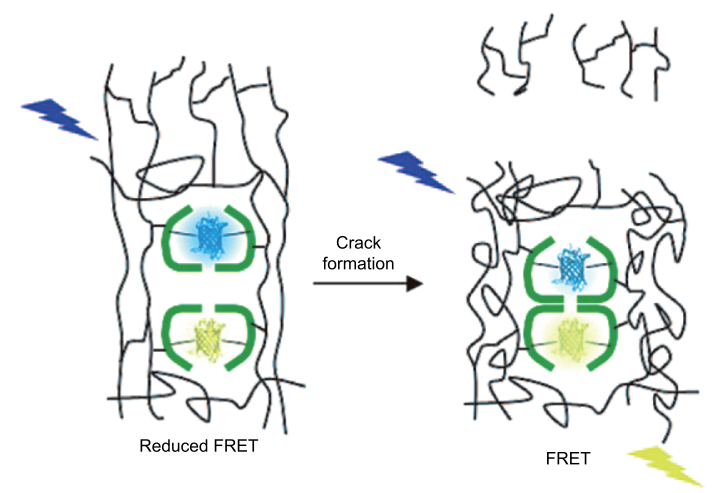

Figure 6 The model of structural deformation comprising an FRET pair of fluorescent proteins co-encapsulated into the two cavities of the thermosome (THS). Deformation of the complex decreases the distance between the fluorescent proteins, resulting in an enhanced FRET process (reproduced with permission from Ref. [72], Copyright 2009, WILEY$\mathrm{VCH})$.
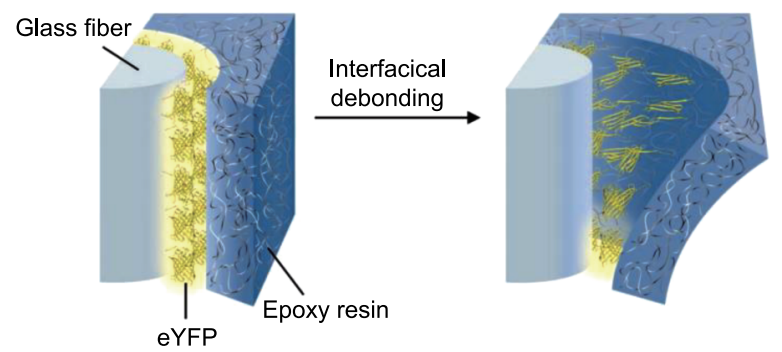

Figure $7 \mathrm{~A}$ concept of fluorescent protein acting as a mechanophore at the fiber-resin interface in fiber-reinforced composites. It reports the occurrence of micro-damage due to low velocity impact. Interfacial de-bonding defects at the fiber-polymer interface cause mechanical unfolding of the protein and thereby a loss of the protein's fluorescence (reproduced with permission from Ref. [73], Copyright 2013, WILEY-VCH).

polymer composites with eYFP as the mechanophore whose fluorescence was highly dependent on its secondary structures. In their case, mechanical perturbation of the $\beta$-barrel structure from the fiber fractures or fiber-matrix de-bonding leads to remarkable change of fluorescence (Fig. 7). Then, Brantley et al. [74] reported the first example of mechanically induced quenching of fluorescence, where a modified green fluorescent protein (GFPuv) was covalently linked into polymers and exhibited fluorescence quenching under mechanical force (Fig. 8). All of these model systems witness the potential application of biomechanical sensors for visually reporting failure and damage on a submit crometer scale before macroscopic cracks become detectable.

Another part of mechanoluminescence, namely, mechano-chemiluminescence, is concerned by converting

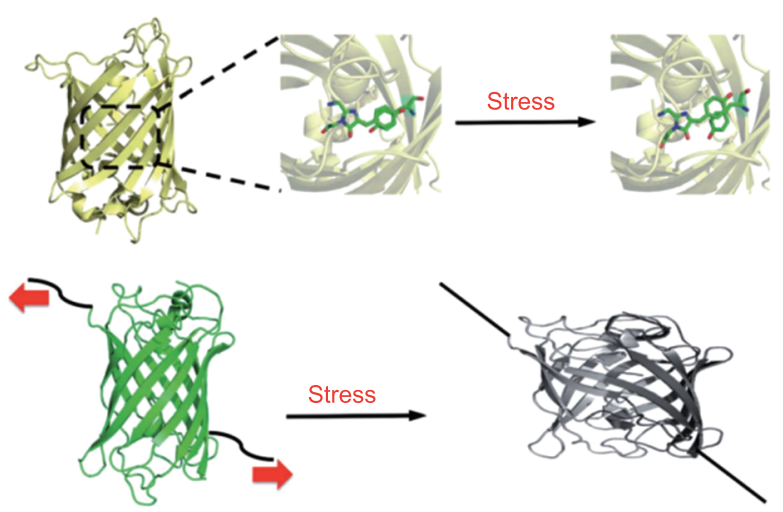

Figure 8 Schematic representation of mechanical activation of fluorescent proteins. (a) Compression of composite materials containing eYFP distort the arene interaction between the chromophore and tyrosine 203. (b) The incorporation of cysteine residues at strategic sites in GFPuv facilitates the covalent attachment of polymer chains to the protein; subsequent compression of the composite mechanically denatures GFPuv and quenches the protein fluorescence (reproduced with permission from Ref. [74], Copyright 2014, WILEY-VCH).

mechanical energy directly into photons without the need for an additional excitation source. Up to now, although only one mechano-chemiluminescence unit was discovered, the progress of this field is exciting, since it opens up new possibilities to sensitively detect bond scission with transient autoluminescence.

The first work of mechano-chemiluminescence was reported by Chen and Sijbesma et al. in 2012 [40]. They designed a chemiluminescent mechanophore from the well-known chemiluminescence 1,2-dioxetane unit [75] which could be activated by acid or heating. Because of its sensitivity, dioxetane luminescence is used extensively in biological assays [76]. Among various 1,2-dioxetane derivatives, bis(adamantyl) 1,2-dioxetane, with energy barrier to decomposition of $35 \mathrm{kcal} \mathrm{mol}^{-1}$, is thermally more labile mainly because of the steric hindrance of the adamantyl substituents [77,78] (Fig. 9). Upon applied mechanical force to the polymers, the centered weakest dioxetane bonds along the polymer chains experience the highest stress and broke firstly: the 4-membered 1,2-dioxetane ring decomposes into two carbonyl (typically ketone) moieties, one of which is in an electronically excited state. When the excited ketone relaxed into the ground state, blue light is emitted. 1,2-Dioxetane linked linear acrylate polymers and polymer networks with dioxetane cross-linkers can give off bright blue luminescence under mechanical stress. Upon stretching and breaking of a bulk sample, or sonicating the polymer solution, chain scission by opening the 1,2-dioxetane unit results in light emission at $420 \mathrm{~nm}$ 

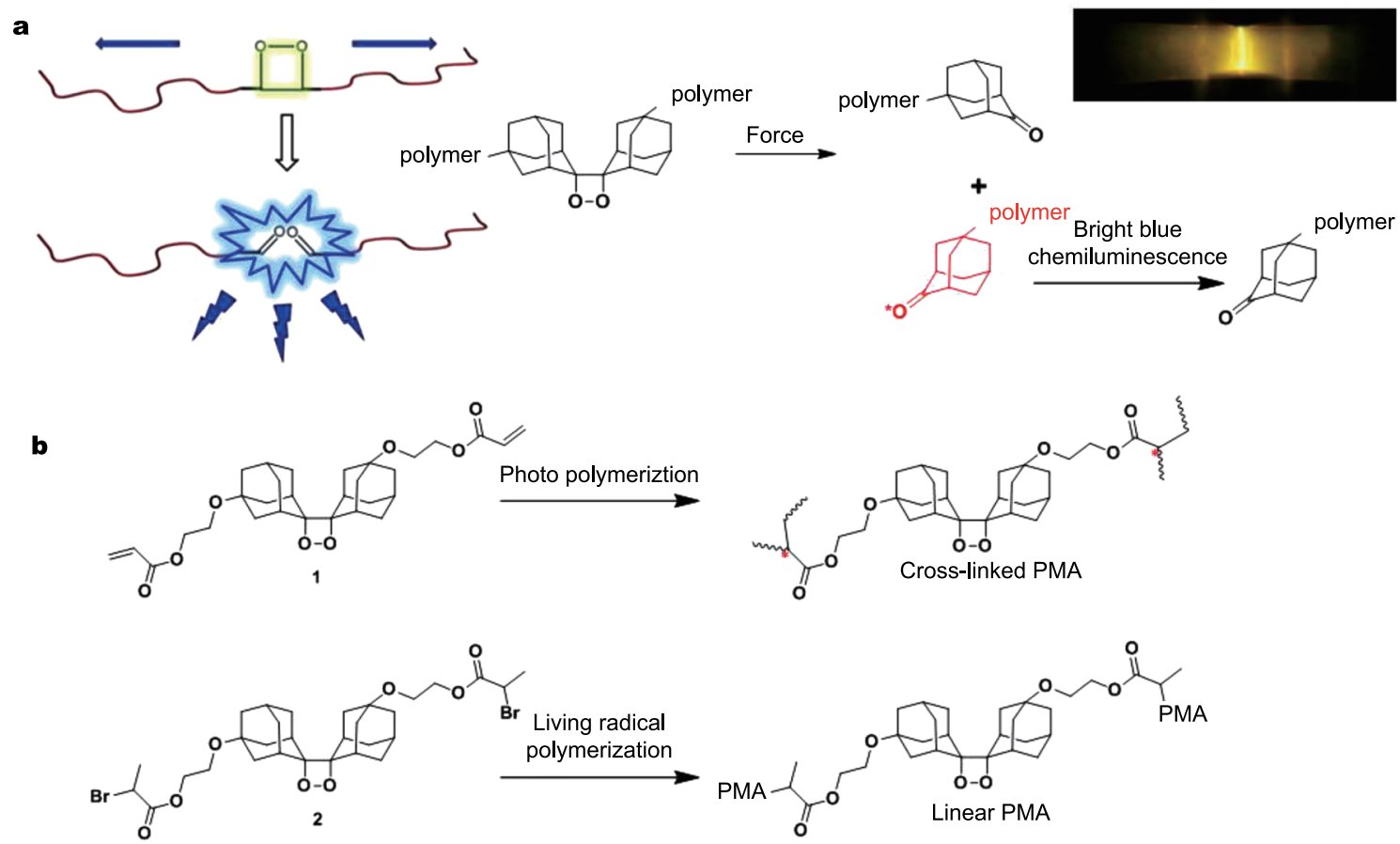

Figure 9 The concept and chemical structures of mechanoluminescence polymers as stress sensor. (a) Schematic representation of mechanically induced chemiluminiscence from polymeric bis(adamantyl)-1,2-dioxetane and a picture of mechanoluminescence film by stretching; (b) scheme of bis(adamantyl)-1,2-dioxetane crosslinked PMA network and linked linear PMA (reproduced with permission from Ref. [40], Copyright 2012, Nature Publishing Group).

within 20 ns of scission. Like in the well-studied thermal equivalent of this process, additional light intensity can be harvested from the non-luminescent triplet excited state by addition of acceptors through energy transfer, enabling tuning of the emission color, and contributing to the high sensitivity of this auto-luminescent system. It was also revealed by the same group that the singlet-triplet ratios and quantum yields of the light were similar under mechanical activation as those under thermal activation.

The results paved the way for subsequent detailed study of stress distribution and evolution in different polymer frameworks. In their following research, 1,2-dioxetane was facilely incorporated into the main chain of a class of segmented copolymers, including polyurethanes, polyesters and polyamides, and performed as a probe to study failure mechanisms of these thermoplastic elastomers (TPE) [41].

Furthermore, these highly sensitive molecular probes for bond scission with auto-luminescence make it possible to distinguish between different mechanisms of failure of polymeric materials. A compelling case was successfully described by the collaboration groups of Creton and Sijbesma, in which the dioxetane mechanophore was used to illustrate a new toughening approach [79]. The authors adapted the double-network principle, once developed for tough hydrogels into the creation of unfilled tough elastomers. Their elastomers were synthesized through sequential free-radical polymerizations. A first UV polymerization of acrylate together with a small amount of bisacrylate led to the cross-linked rubbery network, as referred to single network (SN), and a second UV polymerization was performed on the swollen $\mathrm{SN}$, until all the monomer were consumed. A highly stretched and dilute first network was obtained when the SN was swollen by its acrylate monomer. The isotropically stretched bonds of the first network performed as the sacrificial bonds within pre-programmed stress, so that they can readily absorb mechanical energy, deform and relax the accumulated stress before macroscopic fracturing of the materials, imparting toughness to the elastomers.

Using mechano-chemiluminescent dioxetane as the cross-linker, people could directly see where and when the sacrificial bonds break as the elastomers are failed or threaten to fail. From the crack luminescence map of the mechanical hysteresis experiments, that qualitatively agrees with the models proposed by Tanaka [80] and Brown [81]. The intensity map shows the bonds breaking distribution before crack tip and the dynamic shape of the damage zone (Fig. 10). We anticipate this methodology 


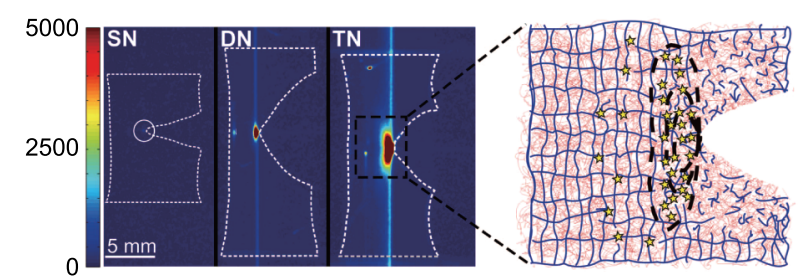

Figure 10 Mapping of where bonds break during crack propagation of SN, DN, and TN samples (left) and schematic representation of the sacrificial bond-breaking mechanism in front of the crack tip for the DN and TN; the first network is represented in blue, and the second and third networks are in red (right) (reproduced with permission from Ref. [79], Copyright 2014, American Association for the Advancement of Science)

using the dioxetane-based spectroscopic probe to illuminate the toughening mechanism of other new materials constructed according to the double-network principle [82].

Dioxetane mechanoluminescence is also helpful to understand the reinforced mechanism of a class of metallosupramolecular gels developed by Kean and co-workers [83]. Their gels consisted of poly(4-vinylpyridine) (P4VP) with a dibromide functional crosslinker in dimethysulfoxide (DMSO) (PN1) and the weak, transient supramolecular cross-linkers with bifunctional van Koten-type pincer complexes [84] were introduced into the PN1 network (Fig. 11). The dynamic and weak nature of supramolecular cross-linkers allowed fine-tuning of the lifetime for the gels and significantly increasing strain at break by distribution stress and inhibiting crack formation. Such a mechanism was proved by tracing the failure induced luminescence a
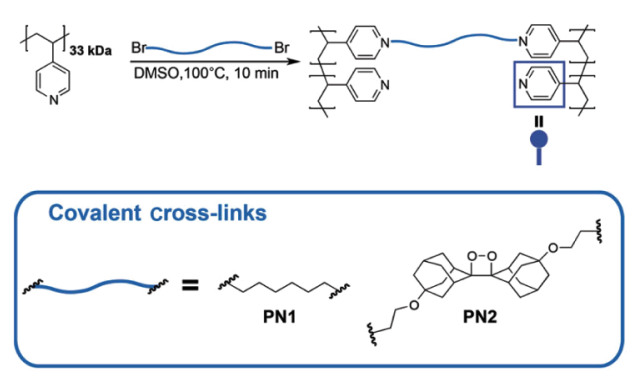

b
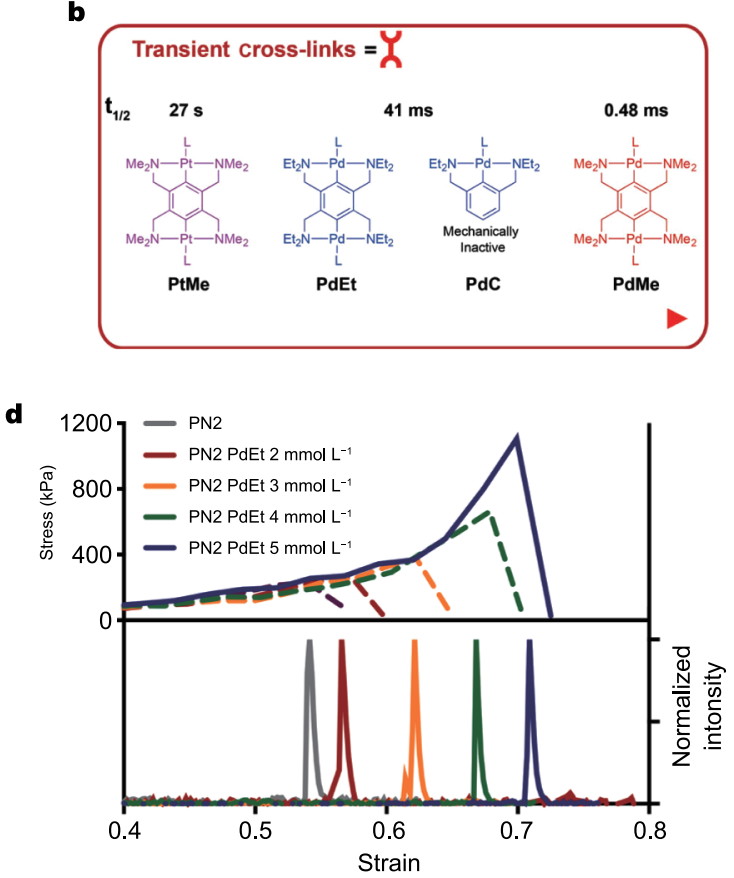

c
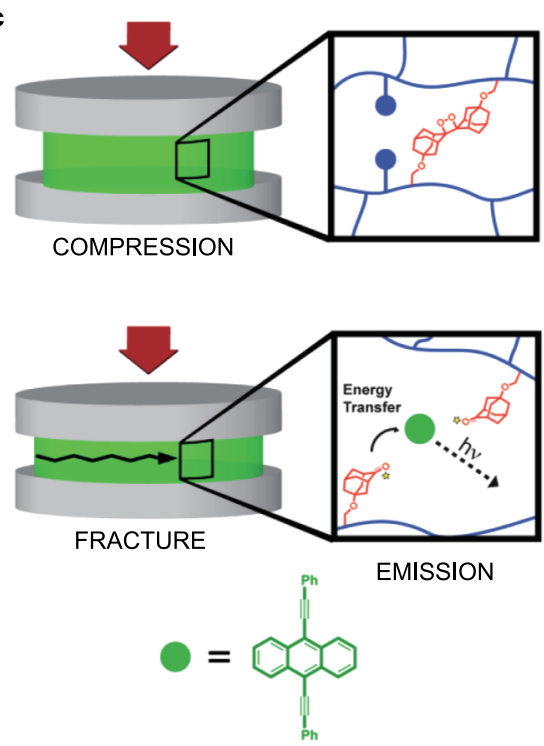

e

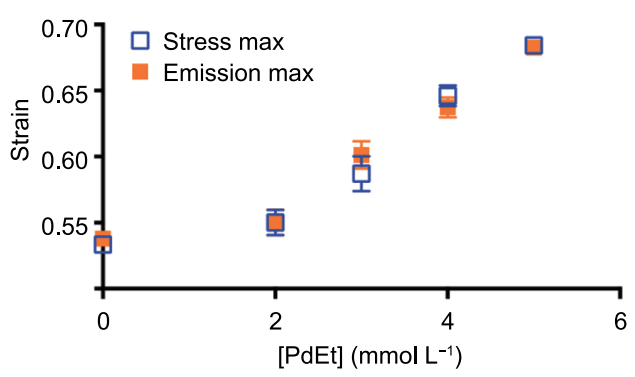

Figure 11 Bis(adamantyl)-1,2-dioxetane as a stress sensor in tough gels (a and b) structures of PN metallosupramolecular gels; (c) schematic representation of probing covalent failure of PN2 network bearing dioxetane-functional crosslinks with mechanically generated chemiluminescence; (d) representative stress-strain and emission intensity-strain plots of PN2.PdEt gels as a function of [PdEt]; (e) strain at emission max and stress max $v$. [PdEt]. Microscopic failure emission max is observed to occur in concert with macroscopically observe failure (stress max) (reproduced with permission from Ref. [83], Copyright 2014, WILEY-VCH) 
of gels that incorporated the dioxetane mechanophore as the covalent cross-linkers (PN2.PdEt, Fig. 11b). PN2.PdEt was subjected to compression testing at various PdEt concentrations and the emission was simultaneously recorded. With increasing the amount of supramolecular cross-linker PdEt, the maximum achievable strain increased and the onset of emission due to failure of the covalent network delayed as well, while the integral emission intensity and duration of emission remained constant. The results indicated that labile non-covalent crosslinks were able to prevent network failure under conditions where they bore virtually zero stress.

\section{CASCADE MECHANOLUMINESCEN CE}

Cascade reaction, also known as domino reaction or tandem reaction, is a chemical process that comprises at least two consecutive reactions such that each subsequent reaction occurs only in virtue of the chemical functionality formed in the previous step [85]. Although widely used in organic synthesis and catalytic process [86], recently, the cascade reaction is employed as well in polymer mechanochemistry. As a specific form of covalent mechanoluminescence, cascade mechanoluminescence involves multi-steps conversion of mechanical energy to luminescence. This research effort is driven by the demand of mechanoluminescence at lower and tunable force thresholds and from various autoluminescent substrates.

In 2012, Baytekin and co-workers [87] found some polymers, such as poly(dimethylsiloxane) (PDMS), tygon and PVC could create radicals by mechanical force, with concomitant $\mathrm{H}_{2} \mathrm{O}_{2}$ as product. Polymer/water interface was proved essential for the mechanical energy conversion, where $\mathrm{H}_{2} \mathrm{O}_{2}$ was generated when the water-filled hollow polymer tubes were squeezed manually. The amount of radical and $\mathrm{H}_{2} \mathrm{O}_{2}$ was increased linearly with the polymer surface area, which were subsequently used to trigger several chemical processes, particularly with fluorescence emission involved when umbelliferone (7-hydroxycoumarin), umbelliferone boronic ester (Fig. 12), as well as redox dyes like methylene blue and neutral red were chosen as the substrates.

The observations on dissociation of coordinating bonds in polymers led to the term "mechanocatalysis", for polymeric metal complexes that can catalyze useful reactions upon the introduction of force. Sijbesma and co-workers made great efforts on mechanochemical activation of latent metal-N-heterocyclic carbene (NHC) coordination polymers as nucleophilic catalysts $[12,23,24]$ or olefin metathesis catalysts [25]. Based on their previous work, this year, they developed palladium bis-NHC complexes which were capable of releasing NHC under sonication. They made use of the high basicity from the free NHC to deprotonate precursor chemiluminescent substrates, 3-(4-methoxyspiro[1,2-dioxetane-3,2'-tricyclo[3.3.1.13,7]decan]-4-yl)phenol and ethyl (5-fluoro-2-oxo-2,3-dihydrobenzofuran-3-yl)carbamate (Fig. 13). Using the cascade strategy, much higher quantum yields were achievable with these chemiluminescent probes [88], therefore, this system was envisaged to be useful in probing bond scission processes with much greater sensitivity and with response to lower force thresholds.

Cascade mechanoluminescence was also achieved in solid state with bis(NHC)-Cu(I) as the mechanophore [89]. Click reaction of phenylaceylene and benzylazide was conducted accompanied by blue fluorescence emission when $\mathrm{Cu}(\mathrm{I})$ center was dissociated as the catalyst site under pressure (Fig. 14).

Although only few cases of chemiluminescence generated in such a catalytic way were described to date, it is worth noting that cascade mechanoluminescence can be achieved at lower force thresholds, which is difficult for that from polymeric bis(adamantyl)-1,2-dioxentane. We anticipate many other fluorescence-triggering reaction systems can be selected and acted as quantifiable probes to detect
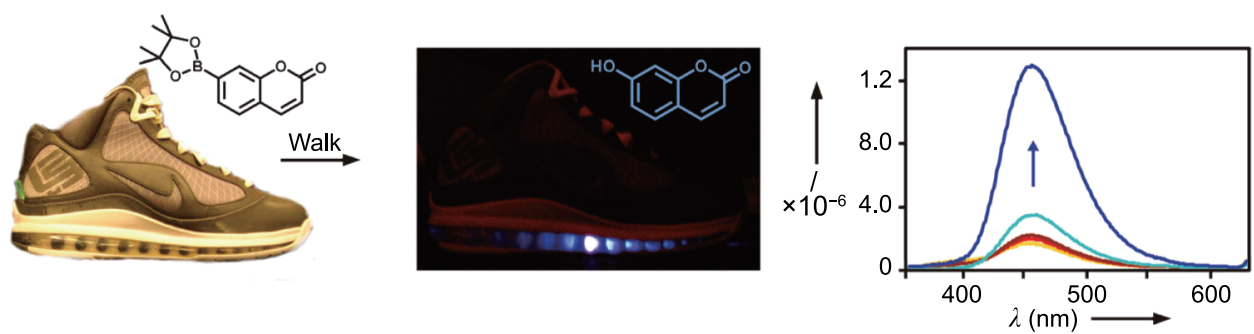

Figure 12 Fluorescent umbelliferone (middle) produced in solution by cleavage of a boronic ester derivative (left) in the voids of the sole of a shoe and fluorescence spectra recorded after $30 \mathrm{~min}$ (yellow), $45 \mathrm{~min}$ (red), $1 \mathrm{~h}$ (brown), $2 \mathrm{~h}$ (light blue) of walking and $24 \mathrm{~h}$ at rest after walking (dark blue) (reproduced with permission from Ref. [87], Copyright 2012, WILEY-VCH). 


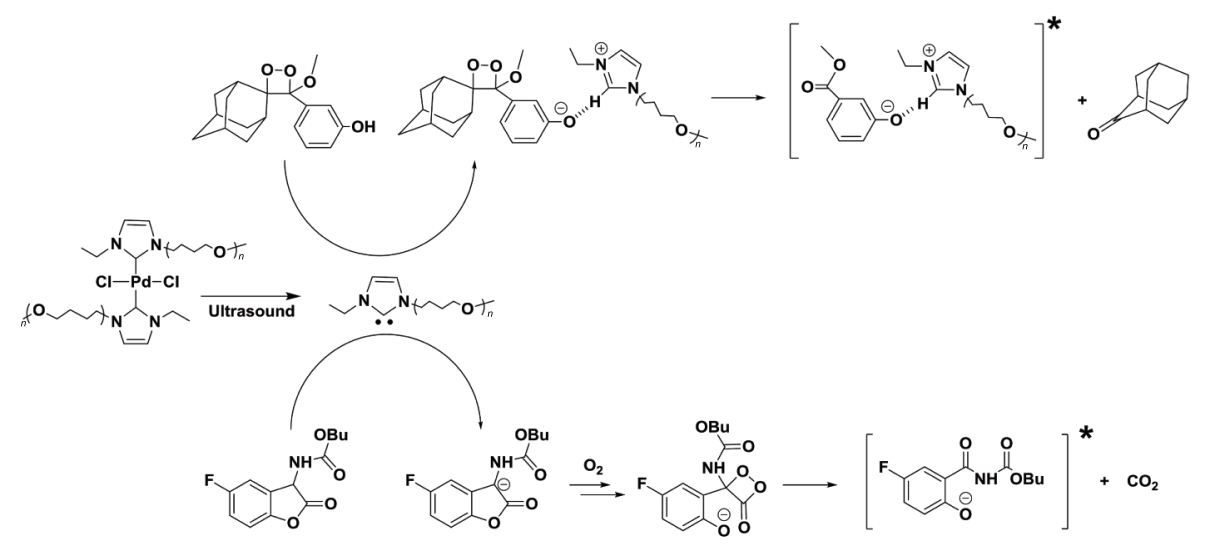

Figure 13 Scission of palladium-NHC coordination polymer, producing free carbine to initiate chemiluminescent decomposition.
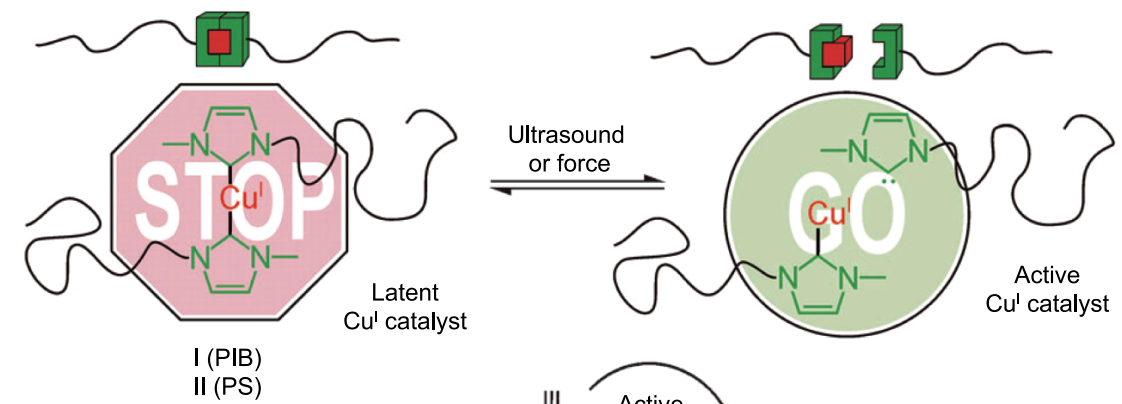<smiles>Nc1cc2ccc(O)cc2oc1=O</smiles>

$=\bigotimes$ Nonfluorescent<smiles>C#Cc1ccccc1</smiles>

(2)
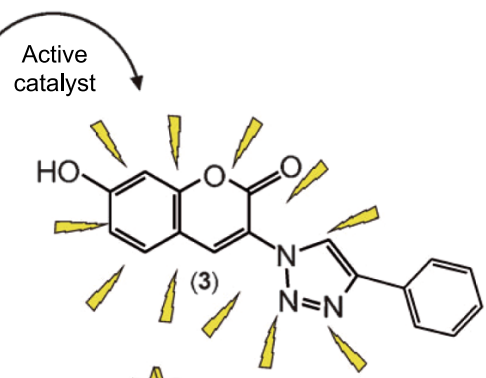

$=\sum^{3}$ Highly fluorescent

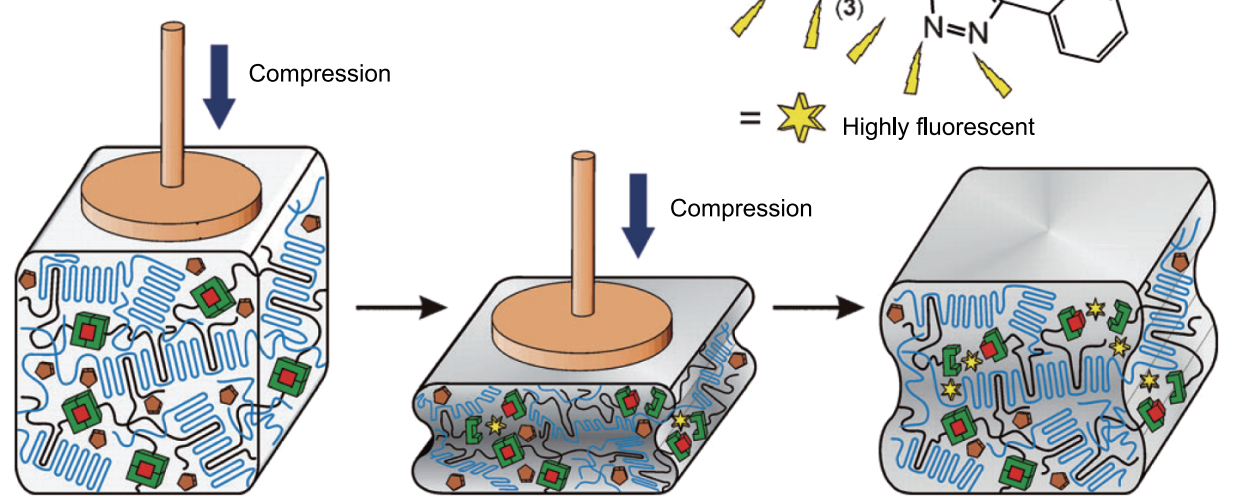

Figure 14 Schematic representation of the activation of latent polymeric $\mathrm{Cu}(\mathrm{I})$-NHC catalysts by ultrasound or compression, to catalyze the fluorogenic "click" reaction of nonfluorescent coumarin dye with ethynylbenzene (reproduced with permission from Ref. [89], Copyright 2015, WILEY-VCH).

force activation.

\section{PERSPECTIVE}

Despite the striding progress demonstrated above, polymer mechanoluminescence is still a challenging research area. Further studies should evolve from the proofs-of-con- cept experiments to their real applications. From a view of material applications, opportunities will arise from the following aspects: (1) combining with modern fabrication techniques and nanoscience, such as three dimensional (3D) printing, micro-/nano-patterning techniques leads to porous polymers and flexible devices 
to increase the efficiency of mechanotransduction and broaden its application scope; (2) remodeling of chemical bonds accompanied with the destructive luminescent process. Instead of destructive, if the mechanical force can be productive in use, reporting and repairing bond scission in polymers will be realized in situ. Recently, researchers are starting to explore this avenue of enquiry. For instance, mechanochromic 3D-printed structures [90] and soft robots [91] have been successfully developed using spiropyran as the mechanophore. As for the self-healing materials, Ramirez [28] and Zhang [27] both demonstrated the mechanochemical strengthening of their synthetic polymers in response to destructive forces, with gem-dibromocyclopropanes and spirothiopyran as the mechanophores, respectively. These pieces of work are inspiring, since we are anticipating huge benefits will be reaped if mechanoluminescence is coupled instead.

\section{CONCLUSION}

At the intersection of mechanics and polymer chemistry, polymer mechanoluminescence therefore has been recognized as a unique bridge that can connect the comprehensive investigations across molecular and macroscopic levels. In this account, we reviewed recent advances in the design and development of mechanoluminescent polymers (encompassing polymers exhibiting mechanically induced chemiluminescent and photoluminescent properties, coupling with polymer composites with cascade visible mechano-responses), and highlighted their prospective applications as molecular-leveled stress sensors. Although most of the results discussed are very recent, it is evident that the emission of photons from a polymer bond (covalently or non-covalently) upon scission offers exciting opportunities to study a host of fundamental processes in polymer failure with unprecedented temporal and spatial resolution. The current success in this field seems certain to continue for the foreseeable future in advanced materials and optoelectronic devices.

\section{Received 28 April 2016; accepted 26 May 2016;} published online 24 June 2016

1 Kaupp G. Mechanochemistry: the varied applications of mechanical bond-breaking. CrystEngComm, 2009, 11: 388-403

2 Takacs L. The historical development of mechanochemistry. Chem Soc Rev, 2013, 42: 7649-7659

3 Caruso MM, Davis DA, Shen Q, et al. Mechanically-induced chemical changes in polymeric materials. Chem Rev, 2009, 109: 5755-5798

4 , . Brantley JN, Bailey CB, Wiggins KM, et al. Mechanobiochemistry: harnessing biomacromolecules for force-responsive materials. Polym Chem, 2013, 4: 3916-3928

5 Messersmith PB. Materials science: multitasking in tissues and ma- terials. Science, 2008, 319: 1767-1768

6 Lv S, Dudek DM, Cao Y, et al. Designed biomaterials to mimic the mechanical properties of muscles. Nature, 2010, 465: 69-73

7 Langer R, Tirrell DA. Designing materials for biology and medicine. Nature, 2004, 428: 487-492

8 Li H, Cao Y. Protein mechanics: from single molecules to functional biomaterials. Acc Chem Res, 2010, 43: 1331-1341

9 Balaz P. Mechanochemistry in Nanoscience and Minerals Engineering. Heidelberg: Springer-Verlag, 2008

10 Staudinger H, Leupold EO. Über Isopren und Kautschuk, 18. Mitteil.: Viscositäts-Untersuchungen an Balata. Ber dtsch Chem Ges A/B, 1930, 63: 730-733

11 Baytekin B, Baytekin HT, Grzybowski BA. Retrieving and converting energy from polymers: deployable technologies and emerging concepts. Energy Environ Sci, 2013, 6: 3467-3482

12 Piermattei A, Karthikeyan S, Sijbesma RP. Activating catalysts with mechanical force. Nat Chem, 2009, 1: 133-137

13 Ramirez ALB, Kean ZS, Orlicki JA, et al. Mechanochemical strengthening of a synthetic polymer in response to typically destructive shear forces. Nat Chem, 2013, 5: 757-761

14 Kryger MJ, Munaretto AM, Moore JS. Structure-mechanochemical activity relationships for cyclobutane mechanophores. J Am Chem Soc, 2011, 133: 18992-18998

15 Klukovich HM, Kean ZS, Iacono ST, et al. Mechanically induced scission and subsequent thermal remending of perfluorocyclobutane polymers. J Am Chem Soc, 2011, 133: 17882-17888

16 Larsen MB, Boydston AJ. "Flex-activated" mechanophores: using polymer mechanochemistry to direct bond bending activation. J Am Chem Soc, 2013, 135: 8189-8192

17 Diesendruck CE, Steinberg BD, Sugai N, et al. Proton-coupled mechanochemical transduction: a mechanogenerated acid. J Am Chem Soc, 2012, 134: 12446-12449

18 Potisek SL, Davis DA, Sottos NR, et al. Mechanophore-linked addition polymers. J Am Chem Soc, 2007, 129: 13808-13809

19 Brantley JN, Bailey CB, Wiggins KM, et al. Mechanobiochemistry: harnessing biomacromolecules for force-responsive materials. Polym Chem, 2013, 4: 3916-3928

20 Black AL, Lenhardt JM, Craig SL. From molecular mechanochemistry to stress-responsive materials. J Mater Chem, 2011, 21: 1655-1663

21 Davis DA, Hamilton A, Yang J, et al. Force-induced activation of covalent bonds in mechanoresponsive polymeric materials. Nature, 2009, 459: 68-72

22 Jacobs MJ, Schneider G, Blank KG. Mechanical reversibility of strain-promoted azide-alkyne cycloaddition reactions. Angew Chem Int Ed, 2016, 55: 2899-2902

23 Groote R, Van haandel L, Sijbesma RP. The effect of molecular weight and catalyst concentration on catalytic activity in mechanochemically activated transesterification using silver(I)- $N$ -heterocyclic carbene latent catalysts. J Polym Sci A Polym Chem, 2012, 50: 4929-4935

24 Jakobs RTM, Ma S, Sijbesma RP. Mechanocatalytic polymerization and cross-linking in a polymeric matrix. ACS Macro Lett, 2013, 2: 613-616

25 Jakobs RTM, Sijbesma RP. Mechanical activation of a latent olefin metathesis catalyst and persistence of its active species in ROMP. Organometallics, 2012, 31: 2476-2481

26 Sottos NR. Polymer mechanochemistry: flex, release and repeat. Nat Chem, 2014, 6: 381-383

27 Zhang H, Gao F, Cao X, et al. Mechanochromism and mechanical-force-triggered cross-linking from a single reactive moiety incorporated into polymer chains. Angew Chem Int Ed, 2016, 55: 
3040-3044

28 Ramirez ALB, Kean ZS, Orlicki JA, et al. Mechanochemical strengthening of a synthetic polymer in response to typically destructive shear forces. Nat Chem, 2013, 5: 757-761

29 Pucci A, Cappelli C, Bronco S, et al. Dichroic properties of bis(benzoxazolyl)stilbene and bis(benzoxazolyl)thiophene dispersed into oriented polyethylene films: a combined experimental and density functional theory approach. J Phys Chem B, 2006, 110: 3127-3134

30 Löwe C, Weder C. Oligo(p-phenylene vinylene) excimers as molecular probes: deformation-induced color changes in photoluminescent polymer blends. Adv Mater, 2002, 14: 1625-1629

31 Kunzelman J, Crenshaw BR, Kinami M, et al. Self-assembly and dispersion of chromogenic molecules: a versatile and general approach for self-assessing polymers. Macromol Rapid Commun, 2006, 27: 1981-1987

32 Kunzelman J, Kinami M, Crenshaw BR, et al. Oligo(p-phenylene vinylene)s as a "new" class of piezochromic fluorophores. Adv Mater, 2008, 20: 119-122

33 Pucci A, Bertoldo M, Bronco S. Luminescent bis(benzoxazolyl)stilbene as a molecular probe for poly(propylene) film deformation. Macromol Rapid Commun, 2005, 26: 1043-1048

34 Pucci A, Dicuia F, Signori F, et al. Bis(benzoxazolyl)stilbene excimers as temperature and deformation sensors for biodegradable poly(1,4-butylene succinate) films. J Mater Chem, 2007, 17: 783-790

35 Wiggins KM, Brantley JN, Bielawski CW. Methods for activating and characterizing mechanically responsive polymers. Chem Soc Rev, 2013, 42: 7130-7147

36 Camara CG, Escobar JV, Hird JR, et al. Correlation between nanosecond X-ray flashes and stick-slip friction in peeling tape. Nature, 2008, 455: 1089-1092

37 Terasaki N, Zhang H, Yamada H, et al. Mechanoluminescent light source for a fluorescent probe molecule. Chem Commun, 2011, 47: 8034-8036

$38 \mathrm{Xu} \mathrm{CN}$, Watanabe T, Akiyama M, et al. Direct view of stress distribution in solid by mechanoluminescence. Appl Phys Lett, 1999, 74: 2414

39 Xu CN, Zheng XG, Akiyama M, et al. Dynamic visualization of stress distribution by mechanoluminescence image. Appl Phys Lett, 2000, 76: 179

40 Chen Y, Spiering AJH, Karthikeyan S, et al. Mechanically induced chemiluminescence from polymers incorporating a 1,2-dioxetane unit in the main chain. Nat Chem, 2012, 4: 559-562

41 Chen Y, Sijbesma RP. Dioxetanes as mechanoluminescent probes in thermoplastic elastomers. Macromolecules, 2014, 47: 3797-3805

42 BP, Mechanoluminescence. In Luminescence of Solids, Boston: Springer US, 1998, 10.1007/978-1-4615-5361-8_10pp 361-389

43 Rheingold AL, King W. Crystal structures of three brilliantly triboluminescent centrosymmetric lanthanide complexes: piperidinium tetrakis(benzoylacetonato)europate, hexakis(antipyrine)terbium triiodide, and hexaaquadichloroterbium chloride. Inorg Chem, 1989, 28: 1715-1719

44 Takada N, Hieda S, Sugiyama J, et al. Mechanoluminescence from piezoelectric crystals of an europium complex. Synthetic Metals, 2000, 111-112: 587-590

45 Takada N, Sugiyama J, Katoh R, et al. Mechanoluminescent properties of europium complexes. Synthetic Metals, 1997, 91: 351-354

46 Li DP, Li CH, Wang J, et al. Synthesis and physical properties of two chiral terpyridyl europium(III) complexes with distinct crystal polarity. Eur J Inorg Chem, 2009, 2009: 4844-4849

47 Zhan TZ, Xu CN, Yamada H, et al. Enhancement of impact-in- duced mechanoluminescence by swift heavy ion irradiation. Appl Phys Lett, 2012, 100: 014101

48 Hurt CR, Mcavoy N, Bjorklund S, et al. High intensity triboluminescence in europium tetrakis (dibenzoylmethide)-triethylammonium. Nature, 1966, 212: 179-180

$49 \mathrm{Xu} \mathrm{H}$, Glumac NG, Suslick KS. Temperature inhomogeneity during multibubble sonoluminescence. Angew Chem Int Ed, 2010, 49: 1079-1082

50 Suslick KS, Flint EB. Sonoluminescence from non-aqueous liquids. Nature, 1987, 330: 553-555

51 Suslick KS, Flannigan DJ. Inside a collapsing bubble: sonoluminescence and the conditions during cavitation. Annu Rev Phys Chem, 2008, 59: 659-683

52 Mcnamara WB, Didenko YT, Suslick KS. Pressure during sonoluminescence ${ }^{\dagger}$. J Phys Chem B, 2003, 107: 7303-7306

53 Suslick KS, Mcnamara WB, Didenko YT. Sonoluminescence temperatures during multi-bubble cavitation. Nature, 1999, 401: $772-775$

54 Flannigan DJ, Hopkins SD, Suslick KS. Sonochemistry and sonoluminescence in ionic liquids, molten salts, and concentrated electrolyte solutions. J Organometallic Chem, 2005, 690: 3513-3517

55 Eddingsaas NC, Suslick KS. Evidence for a plasma core during multibubble sonoluminescence in sulfuric acid. J Am Chem Soc, 2007, 129: 3838-3839

56 Suslick KS, Didenko YT, Mcnamara iii WB. Molecular emission from single-bubble sonoluminescence. Nature, 2000, 407: 877-879

57 Suslick KS, Doktycz SJ, Flint EB. On the origin of sonoluminescence and sonochemistry. Ultrasonics, 1990, 28: 280-290

58 Li J, Nagamani C, Moore JS. Polymer mechanochemistry: from destructive to productive. Acc Chem Res, 2015, 48: 2181-2190

59 May PA, Moore JS. Polymer mechanochemistry: techniques to generate molecular force via elongational flows. Chem Soc Rev, 2013, 42: 7497-7506

60 Wiggins KM, Brantley JN, Bielawski CW. Polymer mechanochemistry: force enabled transformations. ACS Macro Lett, 2012, 1: 623-626

61 Brantley JN, Wiggins KM, Bielawski CW. Polymer mechanochemistry: the design and study of mechanophores. Polym Int, 2013, 62: $2-12$

62 Brantley JN, Wiggins KM, Bielawski CW. Squeezing new life out of polymers. Angew Chem Int Ed, 2013, 52: 3806-3808

63 Pucci A, Bizzarri R, Ruggeri G. Polymer composites with smart optical properties. Soft Matter, 2011, 7: 3689-3700

64 Crenshaw BR, Burnworth M, Khariwala D, et al. Deformationinduced color changes in mechanochromic polyethylene blends. Macromolecules, 2007, 40: 2400-2408

65 Pucci A, Ruggeri G. Mechanochromic polymer blends. J Mater Chem, 2011, 21: 8282-8291

66 Sagara Y, Kato T. Mechanically induced luminescence changes in molecular assemblies. Nat Chem, 2009, 1: 605-610

$67 \mathrm{Wu}$ Y, Hu J, Huang H, et al. Memory chromic polyurethane with tetraphenylethylene. J Polym Sci Part B-Polym Phys, 2014, 52: 104-110

68 Cho SY, Kim JG, Chung CM. A fluorescent crack sensor based on cyclobutane-containing crosslinked polymers of tricinnamates. Sensors Actuators B-Chem, 2008, 134: 822-825

69 Song YK, Lee KH, Hong WS, et al. Fluorescence sensing of microcracks based on cycloreversion of a dimeric anthracene moiety. J Mater Chem, 2012, 22: 1380-1386

70 Kean ZS, Gossweiler GR, Kouznetsova TB, et al. A coumarin dimer probe of mechanochemical scission efficiency in the sonochemical activation of chain-centered mechanophore polymers. Chem 
Commun, 2015, 51: 9157-9160

71 Göstl R, Sijbesma RP. $\pi$-extended anthracenes as sensitive probes for mechanical stress. Chem Sci, 2016, 7: 370-375

72 Bruns N, Pustelny K, Bergeron LM, et al. Mechanical nanosensor based on FRET within a thermosome: damage-reporting polymeric materials. Angew Chem Int Ed, 2009, 48: 5666-5669

73 Makyła K, Müller C, Lörcher S, et al. Fluorescent protein senses and reports mechanical damage in glass-fiber-reinforced polymer composites. Adv Mater, 2013, 25: 2701-2706

74 Brantley JN, Bailey CB, Cannon JR, et al. Mechanically modulating the photophysical properties of fluorescent protein biocomposites for ratio- and intensiometric sensors. Angew Chem Int Ed, 2014, $\mathrm{n} / \mathrm{a}-\mathrm{n} / \mathrm{a}$

75 Turro NJ, Lechtken P, Schore NE, et al. Tetramethyl-1,2-dioxetane. Experiments in chemiexcitation, chemiluminescence, photochemistry, chemical dynamics, and spectroscopy. Acc Chem Res, 1974, 7: $97-105$

76 Beck S, Koster H. Applications of dioxetane chemiluminescent probes to molecular biology. Anal Chem, 1990, 62: 2258-2270

77 Schuster GB, Turro NJ, Steinmetzer HC, et al. Adamantylideneadamantane-1,2-dioxetane. Chemiluminescence and decomposition kinetics of an unusually stable 1,2-dioxetane. J Am Chem Soc, 1975, 97: 7110-7118

78 Meijer EW, Wynberg $H$. The synthesis and chemiluminescence of stable 1,2-dioxetane: An organic chemistry laboratory experiment. J Chem Educ, 1982, 59: 1071-1072

79 Ducrot E, Chen Y, Bulters M, et al. Toughening elastomers with sacrificial bonds and watching them break. Science, 2014, 344 186-189

80 Tanaka Y. A local damage model for anomalous high toughness of double-network gels. Europhys Lett, 2007, 78: 56005

81 Brown HR. A model of the fracture of double network gels. Macromolecules, 2007, 40: 3815-3818

82 Gong JP. Materials both tough and soft. Science, 2014, 344: $161-162$
83 Kean ZS, Hawk JL, Lin S, et al. Increasing the maximum achievable strain of a covalent polymer gel through the addition of mechanically invisible cross-links. Adv Mater, 2014, 26: 6013-6018

84 Albrecht M, Van koten G. Platinum group organometallics based on "pincer" complexes: sensors, switches, and catalysts. Angew Chem Int Ed, 2001, 40: 3750-3781

85 Tietze LF, Beifuss U. Sequential Transformations in Organic Chemistry: A Synthetic Strategy with a Future. Angew Chem Int Ed Engl, 1993, 32: 131-163

86 Nicolaou KC, Edmonds DJ, Bulger PG. Cascade reactions in total synthesis. Angew Chem Int Ed, 2006, 45: 7134-7186

87 Baytekin HT, Baytekin B, Grzybowski BA. Mechanoradicals created in "polymeric sponges" drive reactions in aqueous media. Angew Chem Int Ed, 2012, 51: 3596-3600

88 Clough JM, Balan A, Van daal TLJ, et al. Probing force with mechanobase-induced chemiluminescence. Angew Chem Int Ed, 2016, 55: 1445-1449

89 Michael P, Binder WH. A mechanochemically triggered "click" catalyst. Angew Chem Int Ed, 2015, 54: 13918-13922

90 Peterson GI, Larsen MB, Ganter MA, et al. 3D-printed mechanochromic materials. ACS Appl Mater Interfaces, 2015, 7: 577-583

91 Gossweiler GR, Brown CL, Hewage GB, et al. Mechanochemically active soft robots. ACS Appl Mater Interfaces, 2015, 7: 22431-22435

Acknowledgments This work was supported by the National Natural Science Foundation of China (51503142), the Thousand Youth Talents Plan, and the Natural Science Foundation of Tianjin (15JCYBJC52900).

Author contributions Yuan Y and Chen Y wrote the paper. Yuan W searched and organized the references. All authors contributed to the general discussion

Conflict of interest The authors declare that they have no conflict of interest. 

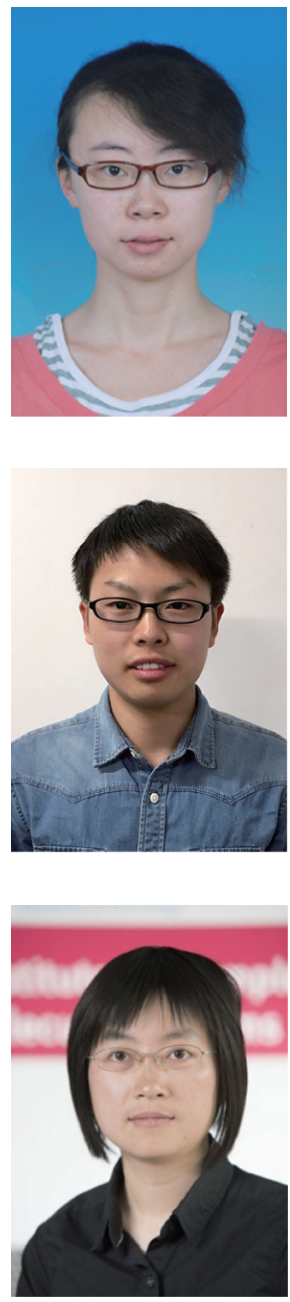

Yuan Yuan received her bachelor degree at Tianjin University. She is currently a $\mathrm{PhD}$ student under the supervision of Prof. Yulan Chen in Tianjin University. Her research interest is polymer mechanochemistry.

Wei Yuan received his bachelor degree at Xianyang normal university. He is currently a master student under the supervision of Prof. Yulan Chen in Tianjin University. His research interest is polymer mechanochemistry.

Yulan Chen received her bachelor degree at Jilin University and PhD degree under the supervision of Prof. Zhishan Bo in the Institute of Chemistry, Chinese Academy of Sciences. She worked as postdoc in Eindhoven University of Technology and Max Planck Institute, under the supervision of Prof. Rint P. Sijbesma and Prof. Klaus Müllen, respectively. Currently, she is an appointed professor at Tianjin University. Her scientific interests include polymer mechanochemistry and stimuliresponsive polymeric materials.

\section{力诱导发光聚合物研究进展}

袁媛, 袁伟, 陈于蓝*

摘要 机械力诱导聚合物发光研究的对象是在不同机械作用刺激下, 可将机械能转换成光的响应性高分子体系. 近年来, 这方面的研究已 成为新兴的高分子化学研究领域. 为吸引更多研究者关注这一领域, 推动其进一步发展, 本文主要综述了基于非共价键体系、共价键体系 和串联反应的机械力诱导发光聚合物的研究进展, 重点关注其在损伤探测、应力传感等方面的应用, 并展望了力诱导发光聚合物在新型 能源转换材料和器件, 以及自修复材料等方面的应用前景. 